\title{
Effect of Nicardipine on Pulmonary Hypertension after Repair of Congenital Heart Defects in Early Postoperative Period
}

\author{
Kazuo Maruyama, Junko Maruyama, Hirofumi Utsunomiya, \\ Kazuhisa Furuhashi, Motoyuki KurobUCHI, \\ Yoshihiko KATAYAMA, Isao YADA \\ and Mannosuke MUNEYUKI
}

\begin{abstract}
We examined the effect of nicardipine and hyperventilatin on pulmonary arterial pressure (PAP) in four patients with pulmonary hypertension in congenital heart defect especially in the early postoperative period. There was a significant positive correlation between the values of arterial carbon dioxide tension $\left(\mathrm{Pa}_{\mathrm{CO}_{2}}\right)$ and the ratio of mean $\mathrm{PAP}$ to mean systemic arterial pressure $(\mathrm{Pp} / \mathrm{Ps})$ in two patients whose Heath Edwards classification was Grade II; one of them also had $20 \%$ reduction of mean PAP by nicardipine without changing mean arterial pressure. In the remaining two patients showing no correlation between the values of $\mathrm{PaCO}_{2}$ and $\mathrm{Pp} / \mathrm{Ps}$, nicardipine did not reduce PAP. Although nicardipine reduced PAP without changing systemic arterial pressure in only one out of four patients, these results suggest that nicardipine may be a drug for control of PAP during weaning phase from the ventilator especially in patients whose PAP decreases under hyperventilation. (Key words: postoperative, pulmonary hypertension, nicardipine, hyperventilation)

(Maruyama K, Maruyama J, Utsunomiya H, et al.: Effect of Nicardipine on pulmonary hypertension after repair of congenital heart defects in early postoperative period. J Anesth 7: 95-101, 1993)
\end{abstract}

A major challenge in postoperative care for patients with pulmonary hypertension associated with congenital heart disease is to prevent or reverse the postoperative pulmonary hypertensive crisis. A combination of mild hyperventilation and vasodilatory

Department of Anesthesiology, Thoracic and Cardiovascular Surgery, and the Intensive Care Unit, Mie University School of Medicine and Mie University Hospital, Tsu, Japan

Address reprint requests to Dr. Maruyama: Department of Anesthesiology, Mie University Hospital, 2-174 Edobashi Tsu, Mie, 514 Japan therapy has been proposed ${ }^{1}$ in the early postoperative period, and weaning from the ventilator can be accomplished with the help of vasodilator drugs ${ }^{2,3}$. The goal of therapy is to maintain mean pulmonary arterial pressure (mPAP) at less than 50 percent of mean systemic arterial pressure $(\mathrm{mAP})^{1,3}$. Because there is no selective pulmonary vasodilator drug at present, proposed strategy is to try several vasodilator drugs, in turn, to find the appropriate one for reducing pulmonary arterial pressure more than systemic 
arterial pressure ${ }^{1}$. Nifedipine and verapamil have been shown to reduce hypoxic pulmonary hypertension in experimental conditions ${ }^{4,5}$, suggesting a possibility for calcium channel blockers in reducing pulmonary arterial pressure in patients with pulmonary hypertension. Most of the clinical data concerning the effects of calcium channel blockers on pulmonary circulation has come from patients with primary pulmonary hypertension ${ }^{6,7}$. Nifedipine and verapamil are effective on occasion to reduce pulmonary arterial pressure (PAP) in these patients. Nicardipine is one of dihydropyridine derivatives structually similar to nifedipine which can be administered intravenously and is currently used to treat systemic hypertension $^{8-10}$. No data is available about the effect of nicardipine on pulmonary hypertension secondary to congenital heart defect during postoperative period, and there seems to be a possibility for this drug to reduce PAP because of its similarity to nifedipine. We examined the effect of nicardipine on pulmonary arterial pressure in patients with preexisting structual changes associated with pulmonary hypertension in congenital heart defect especially in the early postoperative period. We also determined the effect of hyperventilation to the ratio of $\mathrm{mPAP}$ to $\mathrm{MAP}$ (Pp/Ps).

\section{Patients and Methods}

Four consecutive patients with pulmonary hypertension secondary to congenital heart defect were studied: a 41-year-old man, partial anomaly of pulmonary venous return (PAPVR), mPAP $44 \mathrm{mmHg}, \mathrm{Pp} / \mathrm{Ps}$ 0.53; a 5year-old boy, ventricular septal defect (VSD), mPAP 65 mmHg, Pp/Ps 0.94; a 51-year-old man, atrial septal defect (ASD), mPAP $54 \mathrm{mmHg}, \mathrm{Pp} / \mathrm{Ps}$ 0.65; a 1-year-old girl, transposition of great arteries (TGA), left ventric- ular pressure $90 \mathrm{mmHg}$ in systole and $10 \mathrm{mmHg}$ in diastole, right ventricular pressure $75 \mathrm{mmHg}$ in systole and $10 \mathrm{mmHg}$ in diastole. These preoperative cardiac catheterization values were obtained two months before correction except a patient with PAPVR whose catheterization was carried eight months before correction. A lung biopsy was carried out before corrective surgery in the patient with TGA and at the time of corrective surgery in the remaining three patients. Each biopsy section was graded according to the Heath Edwards classification.

Patients were premedicated with intramuscular morphine (0.1-0.2 $\left.\mathrm{mg} \cdot \mathrm{kg}^{-1}\right)$ and scopolamine or atropine $\left(0.01 \mathrm{mg} \cdot \mathrm{kg}^{-1}\right), 45 \mathrm{~min}$ before induction of anesthesia. Anesthesia was induced with fentanyl 0.02$0.1 \mathrm{mg} \cdot \mathrm{kg}^{-1}$ iv followed by pancuronium $0.1 \mathrm{mg} \cdot \mathrm{kg}^{-1}$ iv with $100 \%$ oxygen and maintained with additional fentanyl and $0.04-0.3 \mathrm{mg} \cdot \mathrm{kg}^{-1}$ diazepam when needed. A Portex intratracheal tube was intubated orally. A 19-gauge Teflon catheter was inserted through the elbow of anesthetic circuit to within $5 \mathrm{~mm}$ of the distal end of the endotracheal tube for samplings of expired gas $^{11}$ and was connected to a sampling tube which was connected to a capnograph, Capnomac (Datex, Finland) for the measurement of endtidal carbon dioxide tension $\left(\mathrm{ET}_{\mathrm{CO}_{2}}\right)$. Chlorpromazine (0.45-1.52 $\left.\mathrm{mg} \cdot \mathrm{kg}^{-1}\right)$ was administered to all patients before cardiopulmonary bypass (CPB) with hypothermia at nasopharyngeal temperature of $18.2-27.9^{\circ} \mathrm{C}$. Total amount of fentanyl was $0.08-0.1 \mathrm{mg} \cdot \mathrm{kg}^{-1}$. In all patients, a radial arterial catheter for blood sampling and pressure measurements was placed either before or after induction of anesthesia. In the adult patients (PAPVR, ASD), a Swan-Ganz catheter was inserted via the right internal juglar vein into the pulmonary artery after the termination of CPB. 
Table 1. Individual hemodynamic response to nicardipine in patients with pulmonary hypertension

\begin{tabular}{|c|c|c|c|c|}
\hline $\begin{array}{l}\text { Diagnosis } \\
\text { Age (year) } \\
\text { Heath Edwards Classification }\end{array}$ & $\begin{array}{l}\text { PAPVR } \\
\text { (41) } \\
\text { II }\end{array}$ & $\begin{array}{c}\mathrm{VSD} \\
(5) \\
\text { II }\end{array}$ & $\begin{array}{c}\text { ASD } \\
(51) \\
\text { II }\end{array}$ & $\begin{array}{c}\text { TGA } \\
(1) \\
\text { III }\end{array}$ \\
\hline \multicolumn{5}{|l|}{ Mean arterial pressure $(\mathrm{mmHg})$} \\
\hline Control & 69 & 73 & 72 & 62 \\
\hline Nicardipine & 71 & 70 & 72 & 68 \\
\hline \multicolumn{5}{|l|}{ Heart rate $\left(\right.$ beats $\cdot \min ^{-1}$ ) } \\
\hline Control & 80 & 133 & 100 & 195 \\
\hline Nicardipine & 81 & 134 & 102 & 215 \\
\hline \multicolumn{5}{|c|}{ Mean pulmonary arterial pressure $(\mathrm{mmHg})$} \\
\hline Control & 38 & 50 & 53 & 60 \\
\hline Nicardipine & 36 & $38^{*}$ & 51 & 59 \\
\hline \multicolumn{5}{|l|}{ Ratio of $\mathrm{mPA}$ to $\mathrm{mAP}(\mathrm{Pp} / \mathrm{Ps})$} \\
\hline Control & 0.55 & 0.68 & 0.74 & 0.97 \\
\hline Nicardipine & 0.51 & $0.54^{*}$ & 0.71 & 0.87 \\
\hline \multicolumn{5}{|c|}{ PCWP or left atrial pressure $(\mathrm{mmHg})$} \\
\hline Control & 15 & & 16 & 12 \\
\hline Nicardipine & 15 & & 15 & 11 \\
\hline \multicolumn{5}{|l|}{ Right atrial pressure $(\mathrm{mmHg})$} \\
\hline Control & 9 & 11 & & \\
\hline Nicardipine & 8 & 11 & & \\
\hline \multicolumn{5}{|l|}{ Cardiac output $\left(l \cdot \min ^{-1} \cdot \mathrm{m}^{-2}\right)$} \\
\hline Control & 5.85 & & 6.07 & \\
\hline \multirow{2}{*}{\multicolumn{5}{|c|}{ Pulmonary vascular resistance (dyne $\cdot \mathrm{s} \cdot \mathrm{cm}^{-5}$ ) }} \\
\hline & & & & \\
\hline Control & 316 & & 487 & \\
\hline Nicardipine & 290 & & 552 & \\
\hline
\end{tabular}

Abbreviations: $\mathrm{mPA}$, man pulmonary arterial pressure; $\mathrm{mAP}$, mean arterial pressure; PCWP, pulmonary capillary wedge pressure. ${ }^{*}$ Nicardipine produced changes of more than $20 \%$ of baseline in $\mathrm{mPAP}$ and $\mathrm{Pp} / \mathrm{Ps}$ in a 5 -year-old boy with VSD, but there were no changes in the remaining three patients. See figure 3.

In the two children (VSD, TGA) a pulmonary arterial catheter was placed directly into the pulmonary artery at the termination of CPB. A left atrial catheter was also placed in the patient with TGA. Pressure tracing and postoperative chest $\mathrm{X}$-ray confirmed the correct position of the catheters. Systolic, diastolic and mean pressure obtained electronically in radial and pulmonary arteries were measured during the end-expiratory phase using a cardiac monitor, Life Scope 12 (Nihon Kohden, Japan)
The effect of nicardipine

The effects of nicardipine on hemodynamics were examined under the mechanical ventilation with $\mathrm{Pa}_{\mathrm{CO}_{2}}$ of 35-40 $\mathrm{mmHg}$ within 48 hours after the termination of operation. Dopamine (10-15 $\mu \mathrm{g} \cdot \mathrm{kg}^{-1} \cdot \mathrm{min}^{-1}$ ) had been administered to three patients, but not to the patient with PAPVR. Baseline heart rate, arterial pressure, and pulmonary arterial pressure were recorded in all patients. Left atrial pressure or right atrial pressure was also recorded in patients with the catheters. Cardiac 

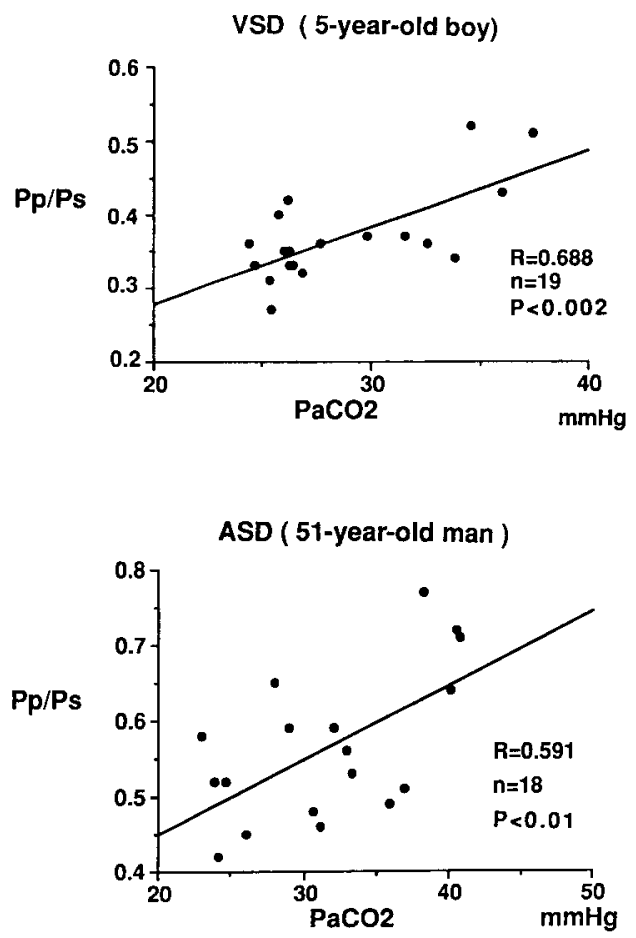

Fig. 1. Correlation between the values of $\mathrm{PaCO}_{2}$ and $\mathrm{Pp} / \mathrm{Ps}$

There was a significant positive correlation between the values of $\mathrm{Pa}_{\mathrm{CO}_{2}}$ and $\mathrm{Pp} / \mathrm{Ps}$ in two patients (VSD, a 5-year-old boy; ASD, a 51-year-old man) whose Heath Edwards classification was Grade II. Abbreviations: $\mathrm{PaCO}_{2}$, arterial carbon dioxide tension; $\mathrm{Pp} / \mathrm{Ps}$, the ratio of mean pulmonary arterial pressure to mean systemic arterial pressure.

output by thermodilution method and pulmonary capillary wedge pressure were measured and total pulmonary vascular resistance was calculated in the two adult patients. After the baseline measurements, an infusion of nicardipine was started at a rate of 1$2 \mu \mathrm{g} \cdot \mathbf{k g}^{-1} \cdot \mathbf{m i n}^{-1}$. These measurements were then repeated $15-30 \mathrm{~min}$ after the start of a continuous nicardipine infusion. We defined a clinically important response to nicardipine as a change in the values greater than $20 \%$.

Correlation between $\mathrm{Pa}_{\mathrm{CO}_{2}}$ and the ratio of $\mathrm{mPAP}$ to $\mathrm{mAP}$ (Pp/Ps)

The patients were hyperventilated for 24-72 $\mathrm{hr}$ postoperatively under 20-30 mmHg of $\mathrm{PaCO}_{2}$, during which normoventilation or mild hypoventilation up to $45 \mathrm{mmHg}$ was instituted with the guide of $\mathrm{ET}_{\mathrm{CO}_{2}}$. The ratio of mPAP to $\mathrm{mAP}$ (Pp/Ps) was recorded and blood gas analysis was carried out at the same time to correlate $\mathrm{PaCO}_{2}$ and $\mathrm{Pp} / \mathrm{Ps}$. The measurements were taken from 8 to 19 times within $72 \mathrm{hr}$ after operation. Linear regression analysis was used to detect whether there were correlation between $\mathrm{Pa}_{\mathrm{CO}_{2}}$ and $P p / P s$. A $P$ value of less than 0.05 was considered statistically significant.

\section{Results}

The results are summarized in table 1. All patients fell into Heath Edwards classification Grade II, except one-year-old girl with TGA who fell into Grade III. A continuous infusion of nicardipine at a rate of 1-2 $\mu \mathrm{g} \cdot \mathrm{kg}^{-1} \cdot \mathrm{min}^{-1}$ did not induce the reduction of systemic arterial pressure in all four patients. Nicardipine produced $20 \%$ reduction of $\mathrm{mPAP}$ in a 5-year-old boy with VSD, but there were no changes in the remaining three patients. There was no increase in either right atrial pressure or left atrial pressure. Cardiac output and pulmonary vascular resistance did not show changes of more than $20 \%$ of baseline values. There was a significant positive correlation between the values of $\mathrm{PaCO}_{2}$ and $\mathrm{Pp} / \mathrm{Ps}$ in two patients (5-year-old VSD, 51-year-old ASD) whose Heath Edwards classification was Grade II (fig. 1, 2); one of them (5-year-old VSD) also had 20\% reduction of mPAP by nicardipine (fig. 3). Patients showing no significant correlation between $\mathrm{PaCO}_{2}$ and $\mathrm{Pp} / \mathrm{Ps}$ had no response to nicardipine either.

\section{Discussion}

There was a significant positive cor- 


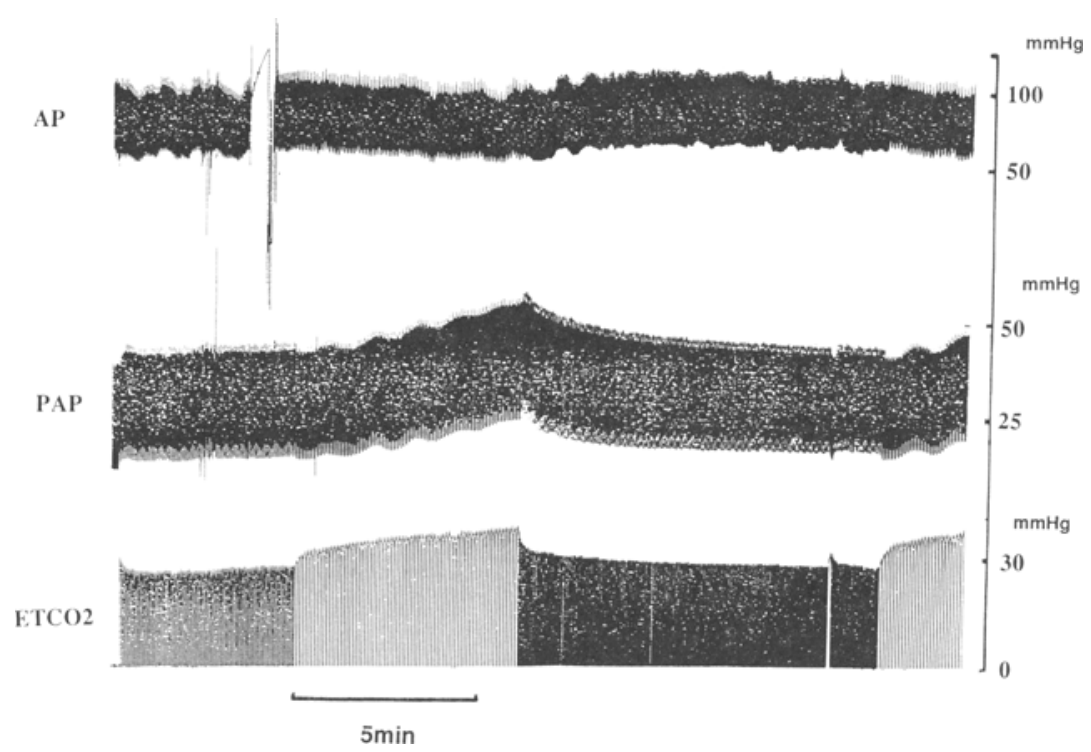

Fig. 2. Representative recordings of arterial pressure, pulmonary arterial pressure and $\mathrm{ET}_{\mathrm{CO}_{2}}$ under hyperventilation and normoventilation.

This recording was obtained from a 5-year-old boy with VSD. The patient was hyperventilated postoperatively under $25-30 \mathrm{mmHg}$ of $\mathrm{PaCO}_{2}$. Normoventilation was instituted with the guide of $\mathrm{ET}_{\mathrm{CO}_{2}}$. Only pulmonary arterial pressure incresased with the increase of $\mathrm{ET}_{\mathrm{CO}_{2}}$. Abbreviations: $\mathrm{AP}$, arterial pressure; PAP, pulmonary arterial pressure; $\mathrm{ET}_{\mathrm{CO}_{2}}$, end-tidal carbon dioxide tension.

relation between the values of $\mathrm{PaCO}_{2}$ and $\mathrm{Pp} / \mathrm{Ps}$ in two patients whose Heath Edwards classification fell into Grade II; one of them had also had $20 \%$ reduction of mPAP by nicardipine without changing $\mathrm{mAP}$.

Oxygen and hyperventilation have the most potent pulmonary vasodilating effect in clinical situations. Patients as risk of developing postoperative pulmonary hypertensive crisis are managed under hyperventilation with 25-30 mmHg of $\mathrm{PaCO}_{2}$ and oxygen administration to keep more than $80 \mathrm{mmHg}$ of arterial oxygen tensin during the postoperative period ${ }^{1,2,3}$. However, pulmonary arterial pressure increases because of the discontinuation of hyperventilation during attemps to wean the patient from the ventilator. In this situation, the rise in pulmonary arterial pressure during weaning phase might be blunted by the use of a vasodilator. Nicardipine produced $20 \%$ reduction in pulmonary arterial pressure without changing arterial pressure in a patient under the normoventilation, suggesting a possibility for this drug to be listed as one of the pulmonary vasodilating drugs. Nicardipine might be effective for the reduction of PAP only in patients whose PAP is reduced by hyperventilation. A further well-controlled study should be necessary to determine the role of nicardipine in the treatment of pulmonary hypertension. Our results also suggest that PAP in patients with Heath Edwards classification Grade II may not always respond to hyperventilation. Although abnormally muscular pulmonary arteries (Heath Edwards grade I) may be hyperreactive to factors such as hypoxia and acidosis and respond to vasodilator drug most effectively ${ }^{12,13}$, arteries with occu- 


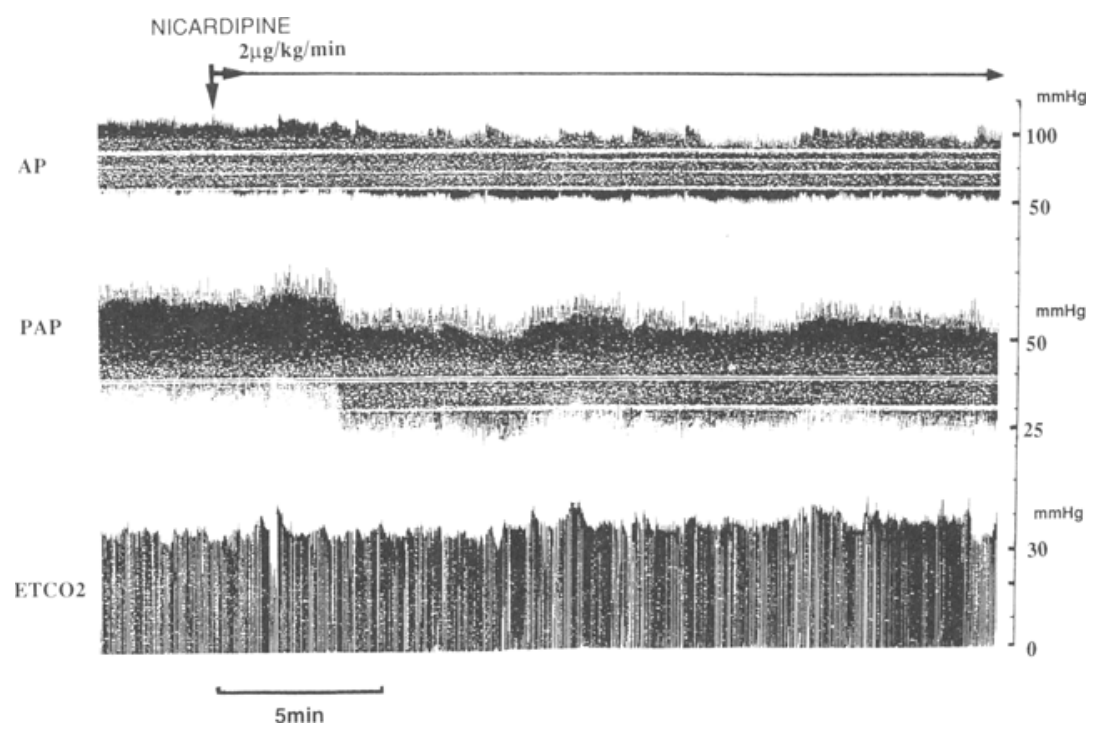

Fig. 3. Recording of arterial pressure and pulmonary arterial pressure in a 5-year-old boy with VSD whose pulmonary arterial pressure was selectively reduced by nicardipine.

Nicardipine produced a $20 \%$ reduction in pulmonary arterial pressure without changing arterial pressure in a 5-year-old boy with VSD under the normoventilation. Abbreviations: same as figure 2 .

lusive changes with intimal hyperplasia (Heath Edwards grades II and III) may not always respond easily to vasodilators.

Although nifedipine is most widely studied, it is not available in an intravenous form ${ }^{8,9,10}$. Varying affinity for different vasculature have been observed among dihydropyridine derivatives ${ }^{9}$. Nifedipine and verapamil might induce some cardiodepressant effect in patients with severe right ventricular dysfunction ${ }^{4}$. The nicardipine selectivity for vascular smooth muscle cells is greater than that of nifedipine ${ }^{8}$ and seems to increase the coronary sinus blood flow more than other calcium channel blockers, suggesting the possibility for the use of this drug in patients with severe congestive heart failure $^{9}$. The problem in the use of vasodilators to reduce pulmonary arterial pressure is that a decrease in systemic arterial pressure tends to be greater than the corresponding decrease in pulmonary arterial pressure. This might lead to profound hypotension producing low coronary blood flow. In the present study, we examined the effect of nicardipine on PAP in the dose without changing AP. Because calcium channel blockers are preferentially active in vasoconstrictive states $^{14,15}$ and baseline APs were normotensive in the present study, 1$2 \mu \mathrm{g} \cdot \mathrm{kg}^{-1} \cdot \mathrm{min}^{-1}$ of nicardipine might not induce reduction in systemic arterial pressure. Consequently in one out of four patients, nicardipine was effective to reduce pulmonary arterial pressure without changing systemic arterial pressure. A higher dose should be tried in the future to determine if nicardipine decreases pulmonary arterial pressure greater than systemic arterial pressure.

We conclude that nicardipine produces $\mathbf{2 0 \%}$ reduction in pulmonary ar- 
terial pressure without changing arterial pressure in at least one patient with pulmonary hypertension associated with congenital heart defect. Nicardipine may be a drug for the control of pulmonary arterial pressure during the weaning phase from the ventilator, especially in patients whose pulmonary arterial pressure decreases under hyperventilation. A further wellcontrolled study is necessary to determine the role of nicardipine in the treatment of pulmonary hypertension more accurately.

(Received Jan. 25, 1992 accepted for publication Apr. 17, 1992)

\section{References}

1. Burrows FA, Klinck JR, Rabinovitch $M$, et al: Pulmonary hypertension in children: perioperative management. Can Anaesth Soc J 33:606-628, 1986

2. Rabinovitch M: Pulmonary circulation in ventricular septal defect. In: Anderson RH, Neches WH, Park SC, Zuberbuhler JR, (Eds). Perspectives in pediatric cardiology., New York: Futura Publishing Co., 1988, pp 6580

3. Rabinovitch M: Pulmonary vascular disease. In: Konstam MA, Isner JM, (Eds). The right ventricle. New York: Kluwer Academic Publishers., 1988, pp 141-184

4. Simonneau G, Escourrou $P$, Duroux $P$, et al: Inhibition of hypoxic pulmonary vasoconstriction by nifedipine. $N$ Eng $J$ Med 304:1582-1585, 1981

5. McMurtry IF, Davidson AB, Reeves JT, et al: Inhibition of hypoxic pulmonary vasoconstriction by calcium antagonists in isolated rat lungs. Circ Res 38:99-104, 1976

6. Packer $M$, Medina $N$, Yushak $M$ : Adverse hemodynamic and clinical ef- fects of calcium channel blockade in pulmonary hypertension secondary to obliterative pulmonary vascular disease. J Am Coll Cardiol 4:890-901, 1984

7. Rubin LJ: Calcium channel blockers in primary pulmonary hypertension. Chest 88:257s-260s, 1985

8. Michel AD, Whiting RL: Cellular action of nicardipine. Am $\mathbf{J}$ Cardiol 64:3H-7H, 1989

9. Singh BN, Josephson MA: Clinical pharmacology, pharmacokinetics, and hemodynamic effects of nicardipine. Am Heart J 119:427-434, 1990

10. Kaplan JA: Clinical considerations for the use of intravenous nicardipine in the treatment of postoperative hypertension. Am Heart J 119:443-446, 1990

11. Burrows FA: Physiologic dead space, venous admixture, and the arterial to end-tidal carbon dioxide difference in infants and children undergoing cardiac surgery. Anesthesiology 70:219225, 1989

12. Tucker A, McMurtry IF, Reeves JT, et al: Lung vascular smooth muscle as a determinant of pulmonary hypertension at high altitude. Am J Physiol 228:762-767, 1975

13. Rabinovitch M, Keane JF, Norwood WI, et al: Vascular structure in lung tissue obtained at biopsy correlated with pulmonary hemodynamic findings after repair of congenital heart defects. Circulation 69:655-667, 1984

14. Fleckenstein A: Specific pharmacology of calcium in myocardium, cardiac pacemakers, and vascular smooth muscle. Ann Rev Pharmacol Toxicol 17:149-166, 1977

15. Milton P: Therapeutic application of calcium-channel antagonists for pulmonary hypertension. Am J Cardiol 55:196B-201B, 1985 